\title{
Application of Bakri balloon in a patient who developed massive postpartum hemorrhage after caesarean section
}

\author{
Banu Öndes, ${ }^{1}$ Ayşe Ender Yumru, ${ }^{1}$ Arzu Şenturk, ${ }^{1}$ Burcu Dincgez, ${ }^{1}$ Murat Bozkurt, ${ }^{2}$ \\ Cengiz Yumru, ${ }^{3}$
}

Keywords: Postpartum, hemorrhage, atony, Bakri balloon, caesarean section

\begin{abstract}
Postpartum hemorrhage is an important emergency in obstetrics. In this study, we present the application of intrauterine balloon tamponade and its outcomes in a patient who developed massive postpartum hemorrhage after caesarean section. A 39- year-old, G5 P3 and 38 weeks pregnant (based on last menstrual period) patient was subjected to emergency caesarean section due to diagnosis of uteroplacental insufficiency and recurrent caesarean section. Four hours after the operation, atony occurred and despite medical treatment the hemorrhage persisted. We inserted a sOS Bakri balloon through the vaginal route and inflated it with $500 \mathrm{cc}$ intracavitary saline for achievement of intrauterine tamponade. Vaginal bleeding ended immediately after the procedure. Use of an intrauterine balloon is an easy-to-apply alternative to surgery that provides rapid hemostasis in serious postpartum hemorrhages.
\end{abstract}

${ }^{1}$ Taksim Education and Research Hospital, Department of Obstetrics and Gynecology, Istanbul, Turkey
${ }^{2}$ Universal Hospitals Group, Department of Obstetrics and Gynecology, Malatya, Turkey

${ }^{3}$ Taksim Education and Research Hospital, Department of Anesthesiology and Critical Care, Istanbul, Turkey

\section{INTRODUCTION}

The incidence of postpartum hemorrhage (PPH) is $3-10 \% \%^{1,2,3}$ Its etiology comprises atony, laceration, placental retention, and coagulopathies. The treatment of PPH includes repairing traumatic lacerations, medical treatment (methergine, prostaglandin F2a, misoprostol), and intrauterine balloon tamponade in cases where the retention curettage fails. When balloon tamponade proves to be ineffective, laparotomy or uterine artery embolization is preferred. The success rate of intrauterine balloon tamponade in $\mathrm{PPH}$ cases is $71-87 \%{ }^{4,5} \quad$ Balloon

Please cite this paper as: Öndes B, Yumru AE, Şenturk A, Dincgez B, Bozkurt M, Yumru C. Application of Bakri Balloon in a patient who developed massive postpartum hemorrhage after Caesarean Section. Proc Obstet Gynecol. 2013;3(3): Article 6 [ 4 p.]. Available from: http://ir.uiowa.edu/pog/. Free full text article.

Corresponding author: Murat BOZKURT, MD. Ismetpaşa cad. Cemal Gürsel Mah. Sefa Apt. No:113/26 44000 MALATYA /TURKEY. Tel: 904222382828/1546- 905322279072. Fax: 904222382600. e-mail jindrmb@yahoo.com.

Financial Disclosure: The authors report no conflict of interest including no connection to any biotechnology manufacturer, pharmaceutical company or other commercial entity.

Received: 6 May 2013; accepted 24 October 2013; POG in Press, 4 November 2013.

Copyright: (c) 2013 Öndes et al. This is an open-access article distributed under the terms of the Creative Commons Attribution License, which permits unrestricted use, distribution, and reproduction in any medium, provided the original author and source are credited. 
tamponade elevates the intrauterine pressure above systemic arterial pressure. ${ }^{6}$ It has several advantages such as rapid achievement of results, cost-effective nature, and being readily implementable in the delivery room. In this study, we discuss the application of intrauterine balloon and its outcomes in a patient who developed massive postpartum hemorrhage after caesarean section.

\section{CASE REPORT}

A 39-year-old and 38 weeks pregnant (based on last menstrual period) patient (gravida 5, para 3) presented to the Gynecology and Obstetrics Clinic of the Taksim Education and Research Hospital because of pain. Initial examination of the patient revealed 2 $\mathrm{cm}$ dilation, pouch positive and partial effacement. Her non-stress test was non-reactive and she had been suffering periodic pain; however, there was no notable deceleration. Sonography examination revealed a single fetus with a positive intrauterine fetal heart rate, markedly reduced amniotic fluid showing strong echo, and middle anterior placenta. Sonography examination displayed two irregular and large lacunes in the placenta in which there was a turbulent flow. A placental insertion anomaly was suspected. Umbilical artery Doppler flows were within normal range, S/D ratio was 1.67 , and $\mathrm{RI}$ was 0.53 . MCA/UmA ratio was above 1 , which was normal. Right uterine artery had a diastolic notch and S/D ratio was 2.27. Initially, we considered the diagnosis to be uteroplacental insufficiency. Left uterine artery demonstrated no diastolic notch. S/D ratio was 1.67. Fetal biometric measurements were consistent with the length of pregnancy and there was no sign indicating an anomaly. The patient, who had a history of 3 caesarean sections and 1 ectopic pregnancy, was subjected to emergency caesarean section due to diagnosis of uteroplacental insufficiency and recurrent caesarean section.

A $3000 \mathrm{~g}$ live female infant $48 \mathrm{~cm}$ in height was delivered. The placenta was on the anterior wall, following the former scar line. Complete manual placenta removal was performed across the scar line with difficulty. Caesarean section was completed accordingly. Bilateral tubal ligation was applied. Due to development of atony at postoperative 4 hours, the presence of a laceration was checked and medical treatment was provided. Since we did not observe any improvement and sonography examination revealed the appearance of hematometra, the patient received uterine coagulum drainage and retention curettage. Because the hemorrhage persisted, we inserted a SOS Bakri balloon through the vaginal route and inflated it with $500 \mathrm{cc}$ intracavitary saline for achievement of intrauterine tamponade. Vaginal bleeding ended immediately after the procedure. The patient received 7 units of erythrocyte suspension and 5 units of TDP transfusion. Upon establishment of stable hemodynamics and hemostasis, the balloon was decompressed by 200c at 24 hours. Since there was no detectable bleeding at 26 hours, the balloon was removed completely. The patient was discharged in a healthy overall condition at postoperative day 6 with a hemoglobin concentration of $11 \mathrm{~g} / \mathrm{dl}$. 


\section{DISCUSSION}

Serious postpartum hemorrhage is encountered in $3-10 \%$ of all live births and is responsible for $28 \%$ of the direct maternal deaths. Postpartum hemorrhage also has an important role in maternal morbidity in addition to mortaility. ${ }^{3}$ Management of postpartum hemorrhage is a life-saving intervention. In treatment, using uterotonic agents is the preferred primary medical treatment.

In case of failure, surgery can be the secondary option. Intrauterine balloon application should be considered as an alternative method in uterine atony when medical treatment fails to succeed. ${ }^{7}$ It has several advantages, making it preferable as an alternative method. These advantages include being readily implementable, costeffective, and capable of eliminating major surgeries such as hysterectomy and their complications in cases with successful outcomes. ${ }^{8,9}$ However, case selection should be carried out meticulously. It cannot be applied in cases of organ failure associated with sepsis after caesarean section or disseminated intravascular coagulation. In the current case, our patient who was subjected to surgery based on the indication of recurrent caesarean section demonstrated ultrasonographic signs supporting placental insertion anomaly. Intraoperatively, the site of placental insertion was observed to be on the former incision line. Manual placenta removal was applied with difficulty. Dabalea et al. reported the success rate of their intrauterine balloon procedures as $80 \%$ for placental invasion and $100 \%$ for atony cases. ${ }^{10}$ In our case, the patient developed atonic hemorrhage at postoperative 4 hours and we applied medical treatment (methergine, prostaglandin $\mathrm{F} 2 \mathrm{a}$, misoprostol) and retention curettage after checking for laceration. Then, we performed intrauterine Bakri balloon procedure according to the algorithm for the management of postpartum hemorrhage. ${ }^{10,11} \quad$ Bleeding was successfully managed. Thus, we were able to discharge our patient in good health at postoperative day 6 without applying any invasive surgery such as uterine artery embolization, uterine or hypogastric artery ligation, B-Lynch suture, or postpartum hysterectomy. In massive secondary postpartum hemorrhage cases, particularly when uterotonic agents fail to succeed in the management of atonies, application of intrauterine balloon spares the patient from laparotomy and yields perfect outcomes. Use of intrauterine balloon is an easy-to-apply alternative to surgery that provides rapid hemostasis in serious postpartum hemorrhages occurring after caesarean section or vaginal birth.

\section{References}

1. Combs CA, Murphy EL, Laros RK Jr. Factors associated with postpartum hemorrhage with vaginal birth. Obstet Gynecol. $1991 \quad J a n ; 77(1): 69-76$. PubMed PMID: 1984230.

2. Magann EF, Evans S, Chauhan SP, Lanneau G, Fisk AD, Morrison JC. The length of the third stage of labor and the risk of postpartum hemorrhage. Obstet Gynecol. $2005 \quad$ Feb;105(2):290-3. http://dx.doi.org/10.1097/01.AOG.00001 51993.83276.70. PubMed PMID: 15684154. 
3. Cameron MJ \& Robson SC. Vital statistics: an overview. In: B-Lynch C, Keith LG, Lalonde AB \& Karoshi M, editors. A Textbook of postpartum hemorrhage : a comprehensive guide to evaluation, management and surgical intervention. Sapiens Publishing; 2006. p. 17-34.

4. Seror J, Allouche C, Elhaik S. Use of Sengstaken-Blakemore tube in massive postpartum hemorrhage: a series of 17 cases. Acta Obstet Gynecol Scand. 2005 Jul;84(7):660-4 DOI: 10.1111/j.0001-6349.2005.00713.x.

PubMed PMID: 15954876.

5. Condous GS, Arulkumaran S, Symonds I, Chapman R, Sinha A, Razvi K. The "tamponade test" in the management of massive postpartum hemorrhage. Obstet Gynecol. 2003 Apr;101(4):76772. http://dx.doi.org/10.1016/S00297844(03)00046-2. PubMed PMID: 12681884.

6. Danso D, Reginald PW. Internal uterine tamponade. In: B-Lynch C, Keith LG, Lalonde $A B$, Karoshi $M$, editors. $A$ Textbook of postpartum hemorrhage : a comprehensive guide to evaluation, management and surgical intervention. Sapiens Publishing; 2006. p. 263-67.

7. Alexander J, Thomas $P$, Sanghera J. Treatments for secondary postpartum haemorrhage. Cochrane Database Syst Rev. 2002;(1):CD002867. PubMed PMID: 11869640.

8. Vitthala S, Tsoumpou I, Anjum ZK, Aziz NA. Use of Bakri balloon in post-partum haemorrhage: a series of 15 cases. Aust N Z J Obstet Gynaecol. 2009 Apr;49(2):191-4. doi: 10.1111/j.1479828X.2009.00968.x. PubMed PMID: 19432609.

9. Lau MS, Tee JC. Use of a large Rusch hydrostatic catheter balloon to control postpartum haemorrhage resulting from a low placental implantation. Singapore Med J. 2009 Sep;50(9):e321-3. PubMed PMID: 19787160.
10. Dabelea V, Schultze PM, McDuffie RS $\mathrm{Jr}$. Intrauterine balloon tamponade in the management of postpartum hemorrhage. Am J Perinatol. 2007 Jun;24(6):359-64. Epub 2007 Jun 13. http://dx.doi.org/10.1055/s-2007984402. PubMed PMID: 17566947.

11. American College of Obstetricians and Gynecologists. ACOG Practice Bulletin: Clinical Management Guidelines for Obstetrician-Gynecologists Number 76, October 2006: postpartum hemorrhage. Obstet Gynecol. 2006 Oct;108(4):103947. PubMed PMID: 17012482. 